\title{
Symptomatic Gastric Adenomyoma in an 84-year- old woman: A case report
}

\author{
Phungreikan Ningshen ${ }^{1}$, Kasomhung Soreingam ${ }^{2}$, Varun K Singh
}

\section{Summary}

Gastric Adenomyoma (GA) is a rare,benign submucosal tumour composed of numerous glands and smooth muscle bundles.We report a 84-year-old woman with recurrent upper abdominal discomfort and a history of malaena. An upper gastrointestinal endoscopy reveal two submucosal swellings in the antrum but the result of endoscopic biopsy was inconclusive.After proper work-up and informed choice,she underwent distal gastrectomy and the final histologic examination reveal gastric adenomyoma.Post-gastrectomy she had no pain but mild satiety and bloating which resolves gradually after 2 months.

GA is rare but should be considered as a possibility in the diagnosis of submucosal gastric tumours.It can be symptomatic and present with malaena even as excision cure it.Surgery should be offered in symptomatic GA even in geriatric patient.

\section{Background}

Gastric Adenomyoma is a rare benign submucosal tumour composed of a mixture of smooth muscle bundles,native glandular structures, brunner's gland,pancreatic duct and acini [1].

It can be asymptomatic or present with non-specific gastrointestinal symptoms such as epigastric pain and vomiting[2,3,4].One earlier reported case present with malaena[4].

We report a case of symptomatic GA in a 84-year-old woman presenting with epigastric discomfort and malaena who is cured by surgery.

\section{Case Presentation}

A 84-year-old woman had recurrent upper abdominal discomfort for the last six months.She had malaena following which she underwent upper gastrointestinal endoscopy one week later on her grandchildren's insistence.It reveals two submucosal tumours at the gastric antrum(Figure1).

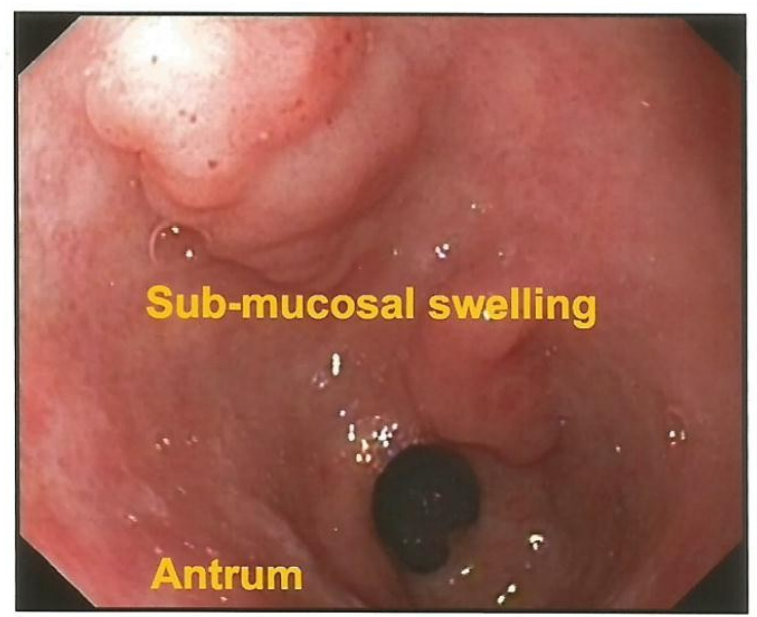

Figure 1: Upper Gastrointestinal endoscopy showing two submucosal swellings in the gastric antrum.

Endoscopic biopsy reveal antral mucosa displaying mucosal glands lined by cells with mild dysplasia and lymphoplasmocytic cell infiltration in the lamina propria.No H.Pylori or evidence of intestinal metaplasia are seen.CECT abdomen was normal.

At this time, the patient first came to my hospital for a second opinion and possible treatment. She has hypertension controlled on regular medication.Further work-up reveal intact cognition,American Society of Anaesthesiologist score of 2 , good nutrition and she can climb two flights of stairs.Labarotory parameters shows haemoglobin $10.2 \mathrm{~g} / \mathrm{dl}$ ( normal range: 12-16), packed cell volume $29 \%$ ( normal range:40- 50\%) mean corpuscular haemoglobin concentration 35.3g/dl(normal range:32-36) and general blood picture reveal 
predominantly normocytic,hypochromic red cells.Echocardiography reveal dilated left atrium,borderline left ventricular enlargement and hypertrophy with ejection fraction of 53\%(modified simpson).Spirometry reveal early small airway obstruction with mild restriction.

After informed choice and pre-operative optimisation,patient was explored. Intra-operatively,serosa was intact and anterior gastrotomy reveal two submucosal tumour of sizes $1.3 \mathrm{~cm} \times 1 \mathrm{~cm}$ and $0.8 \mathrm{cmx} 0.5 \mathrm{~cm}$ in the posterior antrum with intact mucosa.Since frozen section testing is unavailable and considewring her age, Distal gastrectomy with Billroth-2 reconstruction and braun entero-enterostomy was performed.Macroscopic examination reveal vague firm grey white area in submucosa measuring $1 \mathrm{~cm} \times 1 \mathrm{~cm}$ with mildly hyperplastic overlying mucosa.Histology shows numerous benign tubular glands admixed with bundles of smooth muscles in the submucosa with well-preserved mucosa and occasional mucosal glands displaying mild dysplasia.The stroma shows mild lymphoplasmacytic cell infiltration with scattered eosinophil and muscularis propria was mildly hyperplastic .No heterotropic pancreatic tissue is noted in any section(Figure 2).

The second specimen reveal similar findings.

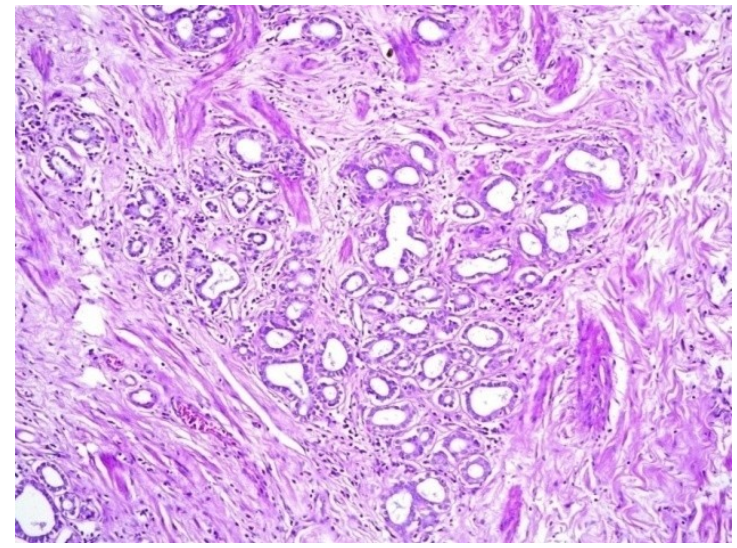

Figure 2 :Microscopy showing numerous benign glands mixed with smooth muscle bundles (HE,x200)

Patient had an uneventful recovery except for mild satiety and bloating which resolves gradually after 2 months.Follow-up endoscopy 6 months later reveal no abnormality (Figure 3).

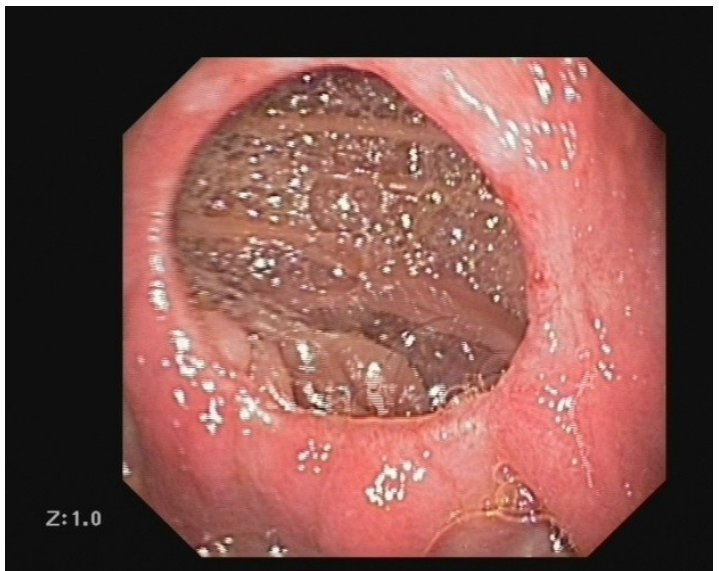

Figure 3 : Post operative upper gastrointestinal endoscopy showing normal gastrojejunostomy anastomosis.

It has been one year that the patient is discomfort-free and she continue to do her usual interests in household chores.

\section{Discussion}

GA is a rare benign submucosal tumour located in the antrum(85\%) and pylorus(15\%)[5].It was first described by Magnus-Alsleben in 1903[2]. Since then,more than 40 cases have been reported with age ranging from 1 week till 81 years of age[3,6,4].To the best of our knowledge, this is the oldest reported patient and who also is symptomatic.

Patient may be asymptomatic or present with vague gastrointestinal complaints such as epigastric pain,dyspepsia and vomiting[2,3,4].There are also reported cases of intermittent pyloric obstruction,case of localised peritonitis and a case of malaena[6,7,4].Our patient present with recurrent upper abdominal discomfort 
and malaena.To the best of our knowledge,this is the second reported case of GA presenting with malaena which we ascribe to mucosal erosions which was healed at the time of endoscopy but pathologic stigmata remains.

Adenomyomas often appear as a roundish or oval shaped mass in the submucosal tissue simulating a lipoma, a neurofibroma, a polypoid formation or a GIST[8]. Our case simulate a lipoma.It is difficult to diagnose pre-operatively and endoscopic biopsy is usually inconclusive because of its submucosal location[8]. With limited resource in this remote part of India we proceed for surgery on the patient and her relatives' wishes.

The definitive diagnosis is usually based on a final post-operative histology report revealing a combination of ducts,glands,pancreatic duct and acini[1].Takeyama et al consider it to be a hamartoma while Barnert $\mathrm{J}$ et al, a special form of heterotropic pancreas[9,10].Our case show numerous tubular glands mixed with smooth muscle bundles without pancreatic tissue.GA has also been seen in association with adenocarcinoma,lymphoma and the question of malignant potential arise[5,11,12].

Because of inconclusive pre-operative diagnosis, resection is advocated for definitive post-operative diagnosis[8].Even radical resection is accepted as the malignant potential is doubtful[3].Zhu $\mathrm{HN}$ et al did frozen section which reveal possible GA and completed with distal subtotal gastrectomy thus avoiding radical surgery[4].Choi YB et al preformed laparoscopic wedge resection with no recurrence after 42 months[13].We perform distal gastrectomy in our case.

Although GA is a rare disease, it has been suggested that it may be more common.

Its varied clinical presentation,difficult pre-operative diagnosis and uncertain malignant potential besides unknown histogenesis and enlightening histology should make an interesting and welcome reporting to eventually formulate a guideline.

With available literature,by now,all symptomatic GA should primarily be treated by surgery even in elderly .

\section{References}

[1]. Stewart TW Jr, Mills LR. Adenomyoma of the stomach. South Med J. 1984 Oct;77(10):1337-8. PMID:6484660 [PubMed indexed for MEDLINE]

[2]. Magnus-Alsleben E. Adenomyome des Pylorus. Virchows Arch 1903; 173: 137-155

[3]. Nabi et al.: Atypical presentation of myoepithelial hamartoma in the antrum of the stomach, mimicking a gastrointestinal stromal tumor: a case report. Journal of Medical Case Reports 2012 6:382.

[4]. Zhu HN, Yu JP, Luo J, Jiang YH, Li JQ, Sun WY. Gastric adenomyoma presenting as melena: A case report and literature review. World J Gastroenterol 2010; 16(15): 1934-1936 Available from: URL: http://www.wjgnet.com/1007-9327/full/ v16/i15/1934.htm DOI: http://dx.doi.org/10.3748/wig.v16.i15. 1934

[5]. Chapple CR, Muller S, Newman J: Gastric adenocarcinoma associated with adenomyoma of the stomach. Postgrad Med J 1988, 64:801-803

[6]. Rhim JH, Kim WS, Choi YH, Cheon JE, Park SH. Radiological findings of gastric adenomyoma in a neonate presenting with gastric outlet obstruction.Pediatr Radiol. 2013 Mar;43(5):628-30. doi: 10.1007/s00247-012-2521-0. Epub 2012 Oct 7.PMID:23052729 [PubMed - indexed for MEDLINE]

[7]. Kagawa S, Fujiwara T, Nishizaki M, Naomoto Y, Hiroshi I, Tanaka N. Adenomyoma of the stomach presenting as localized peritonitis.Dig Dis Sci. 2007 Nov;52(11):3184-7. Epub 2007 Mar 30. PMID:17394080 [PubMed - indexed for MEDLINE]

[8]. Hedenbro JL, Ekelund M, Wetterberg P. Endoscopic diagnosis of submucosal gastric lesions. The results after routine endoscopy. Surg Endosc 1991; 5(1): 20-3.

[9]. Takeyama J, Sato T, Tanaka H, Nio M. Adenomyoma of the stomach mimicking infantile hypertrophic pyloric stenosis. J Pediatr Surg. 2007 Nov;42(11):E11-2. PMID:18022419 [PubMed - indexed for MEDLINE]

[10]. Barnert J, Kamke W, Frosch B. [Adenomyoma of the stomach (pancreatic heterotopia)--case report and review of the literature]. Leber Magen Darm. 1985 Jul;15(4):152-6. German. PMID:4058229 [PubMed - indexed for MEDLINE]

[11]. Agresta F, Della Libera D. Malignant transformation of an adenomyoma of the cardia and malignant Hodgkin gastriclymphoma. An unusual coexistence. Minerva Chir. 2000 Jan-Feb;55(1-2):49-52. PMID:10832284 [PubMed - indexed for MEDLINE]

[12]. Ly DP, Barnard NJ, Schwarz R: Gastric adenomyoma: definitely benign or defiantly premalignant? Dig Dis Sci 2004, 49:19301934.

[13]. Choi YB, Oh ST. Laparoscopy in the management of gastric submucosal tumors. Surg Endosc. 2000 Aug;14(8):741-5. PMID:10954821 [PubMed - indexed for MEDLINE] 